\title{
Aortic Coarctation Severity
}

National Cancer Institute

\section{Source}

National Cancer Institute. Aortic Coarctation Severity. NCI Thesaurus. Code C139037.

The qualitative measurement of the severity of the aortic coarctation. 